\title{
Identification of the function and mechanism of m6A reader IGF2BP2
} in Alzheimer's disease

\author{
Yanyao Deng ${ }^{1}$, Hongwei Zhu ${ }^{2}$, Le Xiao ${ }^{1}$, Chao Liu ${ }^{1}$, Ya-Lin Liu ${ }^{2,3, \&}$, Wenzhe Gao ${ }^{2}$ \\ ${ }^{1}$ Department of Neurology, The First Hospital of Changsha, Changsha, Hunan Province, China \\ 2Department of Hepatopancreatobiliary Surgery, The Third Xiangya Hospital, Central South University, Changsha, \\ Hunan Province, China \\ ${ }^{3}$ Xiangya School of Medicine, Central South University, Changsha, Hunan Province, China \\ Correspondence to: Ya-Lin Liu, Wenzhe Gao; email: 405101308@qq.com, https://orcid.org/0000-0002-6791-0733; \\ gaowenzhexy@csu.edu.cn \\ Keywords: IGF2BP2, N6-methyladenosine, Alzheimer's disease, bioinformatics \\ Received: July 1, 2021 \\ Accepted: October 3, 2021 \\ Published: October 27, 2021
}

Copyright: (C) 2021 Deng et al. This is an open access article distributed under the terms of the Creative Commons Attribution License (CC BY 3.0), which permits unrestricted use, distribution, and reproduction in any medium, provided the original author and source are credited.

\section{ABSTRACT}

Alzheimer's disease, the most common form of dementia in the elderly, is a kind of neurodegenerative disease. However, its pathogenesis and diagnosis remain unclear. M6A is related to nervous system development and neurodegenerative diseases. Here in this study, using multiple RNA-seq datasets of Alzheimer's brain tissues, along with bioinformatic analysis, we innovatively found that m6A reader protein IGF2BP2 was abnormally highly expressed in Alzheimer's patients. After compared between Alzheimer's and normal brain samples, and between IGF2BP2- high and IGF2BP2- low subgroups of Alzheimer's patients, we took the shared differentially expressed genes as the relevant gene sets of IGF2PB2 affecting Alzheimer's disease occurrence for subsequent analysis. Then, weight gene correlation analysis was conducted and 17 functional modules were identified. The module that most positively correlated with Alzheimer's disease and IGF2PB2-high subgroups were mainly participated in ECM receptor interaction, focal adhesion, cytokine-cytokine receptor interaction, and TGF-beta signaling pathway. Afterwards, a hub gene-based model including 20 genes was constructed by LASSO regression and validated by ROC curve for Alzheimer diagnosis. Finally, we preliminarily elucidated that IGF2BP2 could bind with mRNAs in a m6A-dependent manner. This study first elucidates the pathogenic role of IGF2BP2 in Alzheimer's disease. IGF2BP2 and its relevant m6A modifications are potential to be new diagnostic and therapeutic targets for Alzheimer's patients.

\section{INTRODUCTION}

About 50 million people worldwide suffer from dementia, and one case of dementia occurs every 3 seconds [1]. Alzheimer's disease (AD), the most common form of dementia in the elderly, is a kind of neurodegenerative disease. More than 20 million people worldwide are suffering from $\mathrm{AD}[2,3]$. AD usually manifests symptoms such as cognitive impairment and memory loss [4, 5], and the main pathological manifestation of $\mathrm{AD}$ is insoluble neurotoxic aggregates accumulation, including extracellular amyloid plaques formed by amyloid- $\beta$ and neurofibrillary tangles in nerve cells composed of tau protein [6]. Studies have shown that people with abnormal amyloid have more rapid progression of cognitive decline than that without biomarker evidence of amyloid- $\beta$ deposition [7-9]. Though amyloid- $\beta$ can be regarded as the first biomarker becoming abnormal in $\mathrm{AD}$ patients [10-13], both amyloid- $\beta$ and tau protein deposits are required for neuropathologic diagnosis $[14,15]$. The traditional diagnosis still has some limitations. So far, the specific pathogenesis of $\mathrm{AD}$ is still largely unknown, such as how these proteins are related to each other, and what cause them to accumulate to such destructive levels [1], and its 
more exactly biological diagnosis is still on the way. Additionally, gene and protein expression profiles changes support the dysfunction during many basic cellular processes in AD pathogenesis [16]. One of the potential mechanisms for altered expression of $\mathrm{AD}$ related genes involves disruption of the epigenome through disease-specific changes in chromatin structure and/or transcriptional programming [17]. These include changes in DNA methylation [18, 19] and histone modification [20-22]. Besides, the diagnosis of AD still faces great difficulties, in which biomarkers are more important than clinical manifestations to provide a breakthrough basis [1].

Chemical modifications in RNA have become an important mechanism for controlling gene expression and protein translation [23]. N6-methyladenosine (m6A) is the most common and reversible posttranscriptional modification of eukaryotic mRNA [24], and it is also a multifunctional regulator of mRNA splicing, localization, translation and stability $[25,26]$. Methyltransferases (regarded as m6A "writers"), demethylases (regarded as m6A "erasers"), and binding proteins (regarded as m6A "readers") selectively recognize methylated RNA to perform regulatory functions [27]. The brain is rich in m6A which plays a broad role in adult brain development and function [28-30]. M6A is proven to be related to nervous system development and neurodegenerative diseases [31-33]. M6A RNA methylation is considered to be a new frontier in neuroscience, which can provide us with a new perspective in the understanding of neurodevelopment and neurological diseases. Moreover, increasing evidence has revealed that the m6A signaling pathway is closely associated with learning and memory, whose impairments are typical clinical manifestations of $\mathrm{AD}[32,34-38]$. On the other hand, as a neuron surface protein, m6A can promote axon growth, synapse formation and spine induction [39-41]. Insulin-like growth factor $2 \mathrm{mRNA}$ binding protein 2 (IGF2BP2) acts as a reader to regulate m6A [42]. However, whether IGF2BP2 can be used as a marker and auxiliary diagnosis of $\mathrm{AD}$ remains to be determined.

Based on the Gene Expression Omnibus database (GEO), we identified m6A regulator IGF2BP2, whose increase is closely related to $\mathrm{AD}$. Furthermore, we conducted modular exploration to explore the potential mechanism of IGF2BP2 in AD. Finally, we constructed and validated a diagnostic model for $\mathrm{AD}$. Our findings suggested that IGF2BP2 may serve as a novel diagnostic biomarker and its increase might associated with $\mathrm{AD}$ through m6A mechanism. The gene-based diagnostic model provided us a new way on accurate diagnosis of AD.

\section{RESULTS}

\section{M6A reader gene IGF2PB2 was highly expressed in $\mathrm{AD}$}

Based on published literature [43, 44], we brought 19 m6A-related genes into our analysis, and the expression levels of these 19 genes were extracted from 624 samples of GSE33000. Differentially expressed analysis showed that among the $19 \mathrm{~m} 6 \mathrm{~A}$ regulators, the expression of IGF2PB2 in AD patients was significantly higher than that of normal brains (Figure 1A). Further comparison of IGF2PB2 expression between $\mathrm{AD}$ and normal samples in three data sets (GSE33000, GSE48350 and GSE5281) also showed that IGF2BP2 expressed more in AD patients than in normal people (GSE33000: $\log 2$ FoldChange $=0.170, \mathrm{p}<2.22 \mathrm{e}-16$, Figure 1B; GSE48350 and GSE5281: $\log 2$ FoldChange = $1.488, \mathrm{p}=1 \mathrm{e}-11$, Figure 1C). Moreover, considering the heterogeneity of brain tissue, we also explored the expression of IGF2BP2 in different brain regions in GSE48350. It showed that IGF2BP2 was highly expressed in entorhinal cortex, hippocampus, postcentral gyrus and superior frontal gyrus in AD patients compared with normal tissue (Figure 1D). These results preliminarily indicated that IGF2PB2 was abnormally highly expressed in $\mathrm{AD}$ patients, this phenomenon might be related to the pathogenesis and development of AD.

To further find genes that related to IGF2BP2 in AD, first of all, we obtained 13968 differentially expressed genes (DEGs) between $\mathrm{AD}$ and normal tissues in GSE33000 (Figure 2A, 2B). Among them, there were 6918 increased genes and 7050 decreased genes in AD patients. Then, we divided AD patients into two groups according to the median expression level of IGF2PB2 and compared to get 9908 DEGs related to IGF2PB2 expression status (Figure 2C-2E). After intersecting the two DEG sets, we took the shared genes as the relevant gene sets of IGF2PB2 affecting AD occurrence for subsequent analysis.

Given that IGF2BP2 had obvious abnormal expression in $\mathrm{AD}$, we also explored the expression of canonical systemic inflammation biomarkers as well as $\mathrm{AD}$ pathological markers [45, 46] in IGF2BP2_high and IGF2BP2_low subgroups defined by the median expression value of IGF2BP2 in both GSE33000 and GSE48350/5281 datasets (Figure 2F, 2G). It turned that the expression of Complement component C1Q (C1QA, $\mathrm{C} 1 \mathrm{QB}$ and $\mathrm{C} 1 \mathrm{QC}$ ) and $\mathrm{C}$ reactive protein (CRP) was significantly higher in IGF2BP2_high subgroup in AD patients, with no significant difference in $\mathrm{C} 3$, suggesting that IGF2BP2 could exacerbate the inflammatory response in the brain tissue of AD patients. Furthermore, the mRNA expression level of $\beta$ amyloid (A $\beta$ ) and Tau 
A

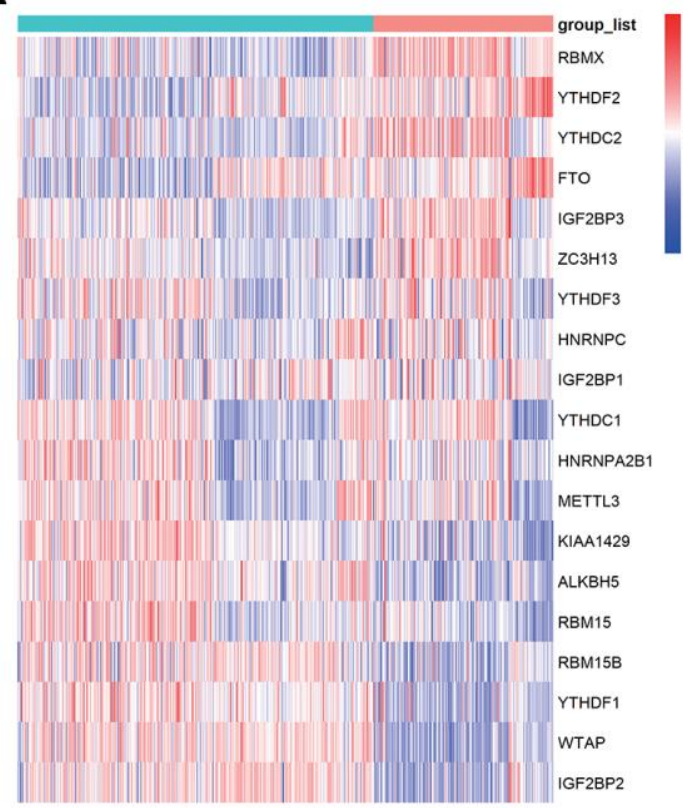

B

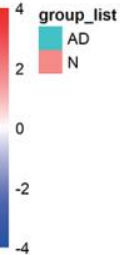

c
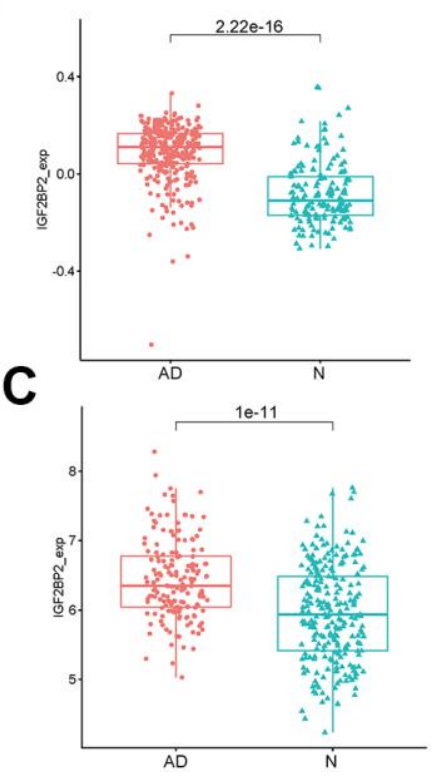

D

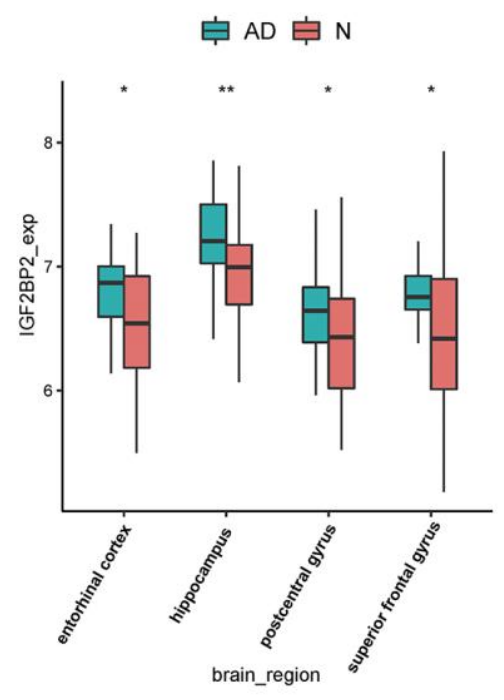

Figure 1. Identification of DEGS in AD. (A) The expression of 19 m6A modification-related genes in GSE33000. (B) IGF2BP2 expression in AD patients and in normal people in GSE33000. (C) IGF2BP2 expression in AD patients and in normal people in GSE48350 and GSE5281. (D) IGF2BP2 expression in different brain regions of AD patients in GSE33000.

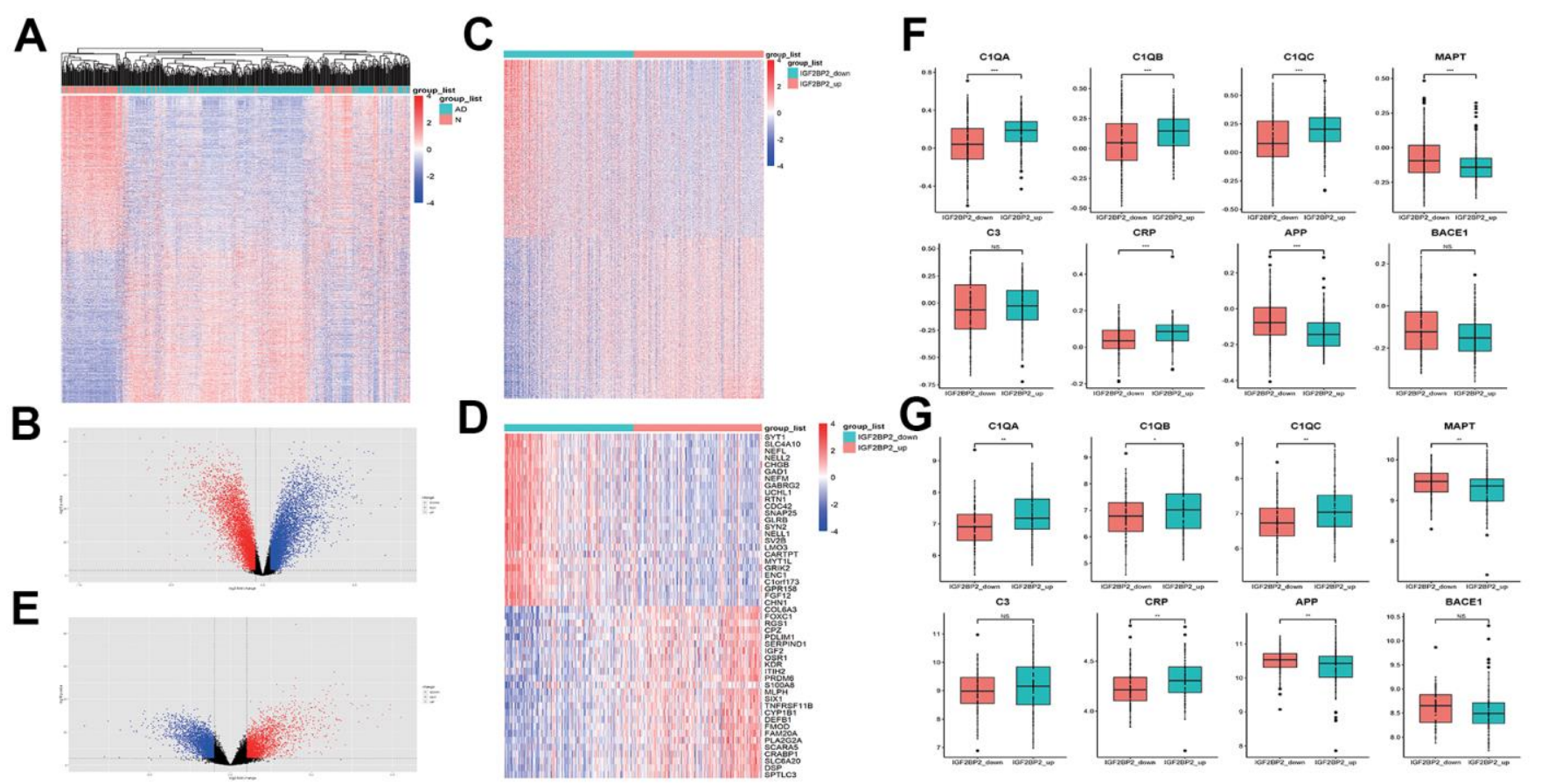

Figure 2. Identification of DEGS related with IGF2PB2 in AD. (A, B) DEGs between AD patients and normal people in GSE33000. (C, E) DEGs between IGF2PB2 high and low group in AD patients in GSE33000. (D) The top25 increased differentially expressed genes and the top25 decreased differentially expressed genes between IGF2PB2 high and low group in AD patients in GSE33000. (F, G) Expression status of systemic inflammation biomarkers and AD pathological markers in IGF2BP2_high and IGF2BP2_low subgroups of AD patients in GSE33000 (F) and GSE48350/5281 (G) datasets. 
protein, showed by their corresponding genes APP and MAPT, was abnormally lower in IGF2BP2_high subgroup, but the expression of BACE1, the key lyase in the formation of $\mathrm{A} \beta$ was not influenced. These results indicated that IGF2BP2 high expression might correlated with the increased expression of APP and MAPT gene variants rather than the normal genes, but further results based on next-generation sequencing were needed to verify our hypothesis.

\section{Module associated with IGF2BP2 in AD}

In order to find the key modules most relevant to IGF2BP2 expression status in $\mathrm{AD}$, we performed weight gene correlation analysis (WGCNA) using the expression profiles of the abovementioned DEGs which related to the expression level of IGF2PB2, thereby identifying 17 modules (Figure 3A). Among them, the black module composed of 440 genes had the most

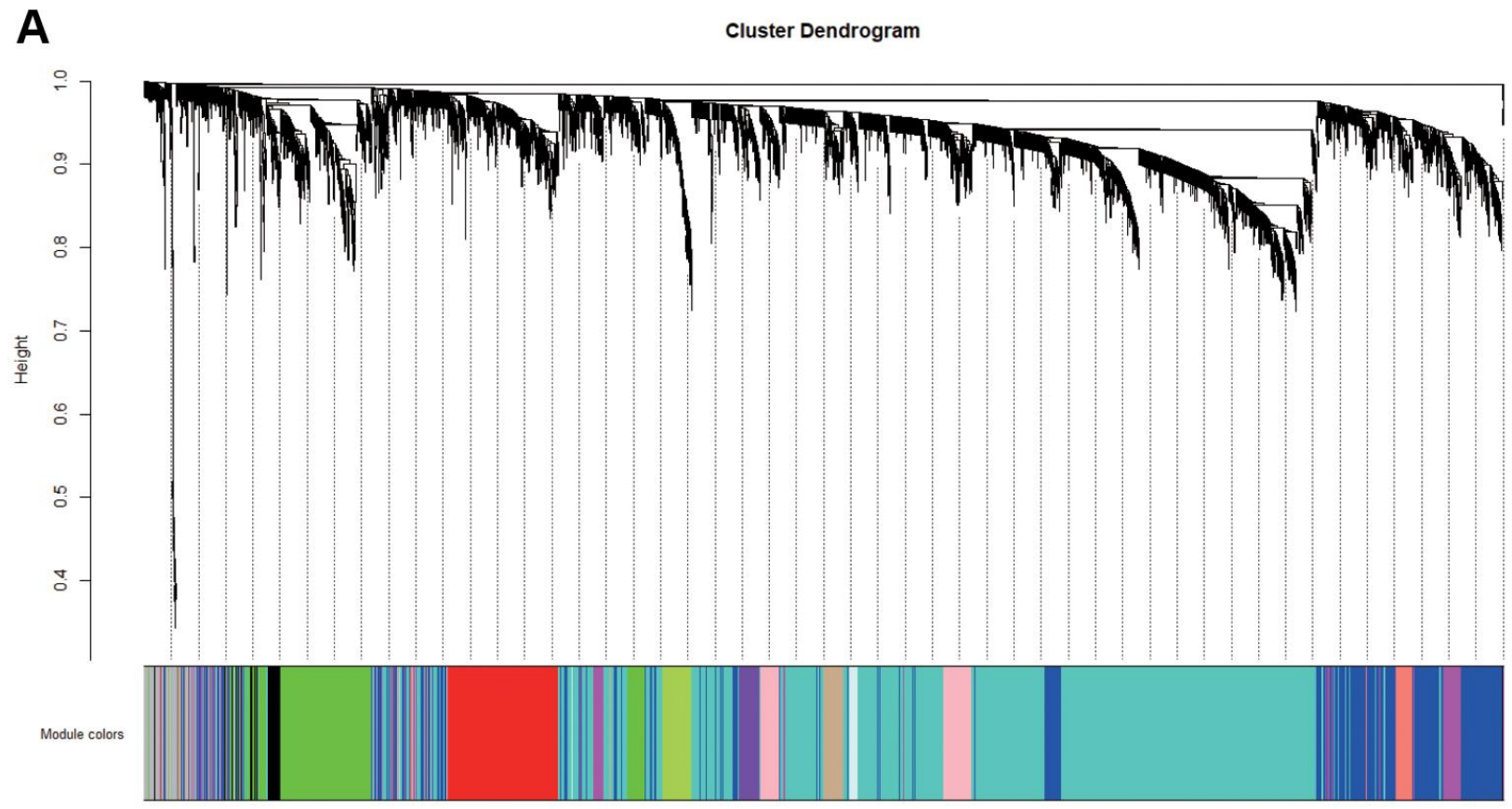

B

Module-trait relationships

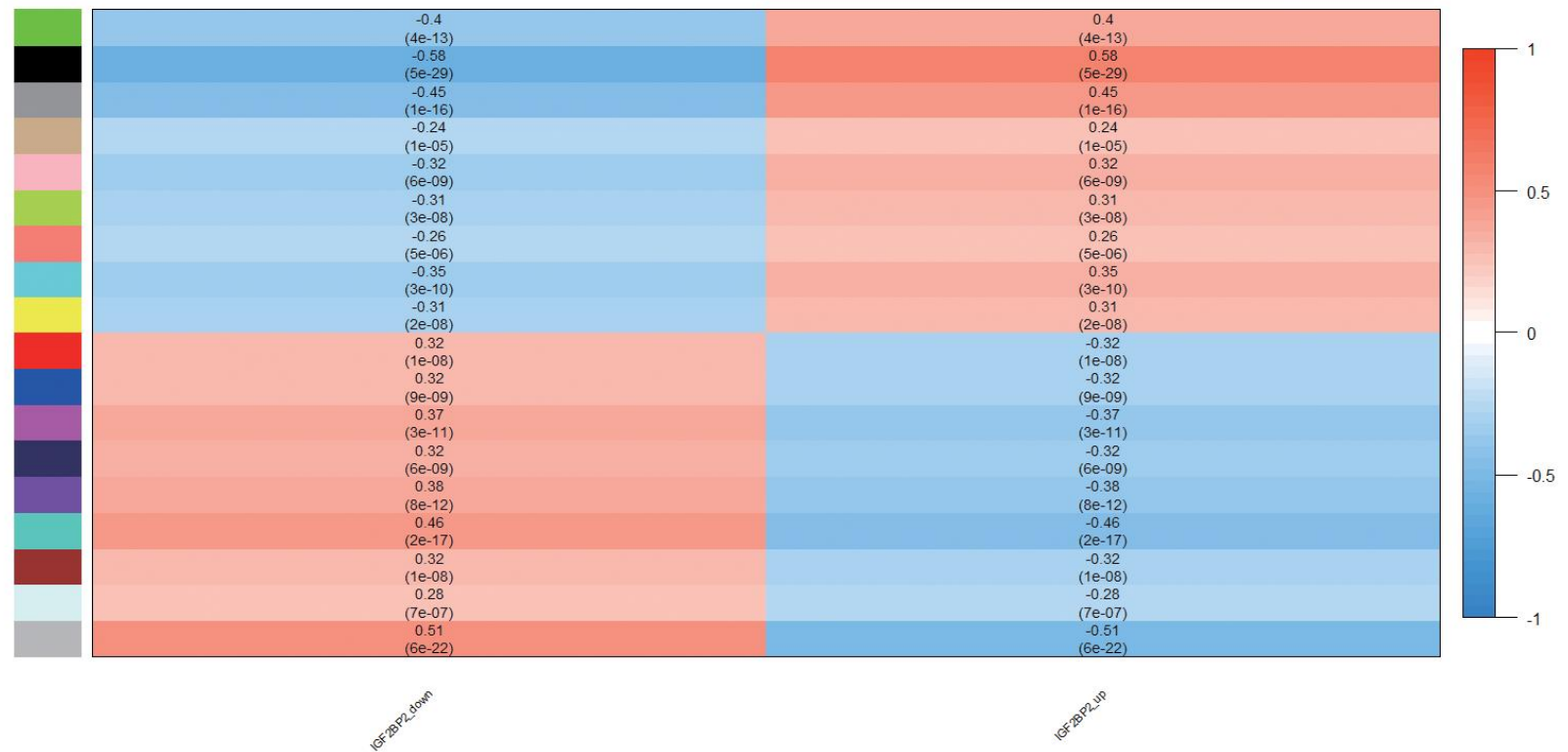

Figure 3. Module associated with IGF2BP2 in AD. (A, B) 17 modules related to the expression level of IGF2PB2 analyzed by WGCNA. 
significant positive correlation with the increase of IGF2BP2 expression (correlation coefficient $=0.58$, $\mathrm{P}=5 \mathrm{E}-29$; Figure $3 \mathrm{~B}$ ), while the turquoise module had the most significant negative correlation (correlation coefficient $=-0.46, \mathrm{P}=2 \mathrm{E}-17$; Figure $3 \mathrm{~B}$ ). Since IGF2BP2 recognized m6A-modified RNA to enhance its stability and increase translation, we paid more attention to the module that had a positive correlation with IGF2BP2 expression, which was the black module. Finally, according to $\mathrm{GS}>0.4$ and $\mathrm{MM}>0.9$, the 440 genes in the black module were further reduced to 65 genes, which were defined as the hub genes with the strongest positive correlation with IGF2BP2 expression.

\section{Pathway analysis for hub genes that positively related to IGF2BP2}

GO and KEGG analysis for 440 genes in the black module were first conducted. Results showed that DEGs was significantly enriched in biological processes such as extracellular structure organization and extracellular matrix organization by GO term enrichment analysis (Figure 4A). In addition, KEGG analysis indicated that DEGs was most significantly enriched in complement and coagulation cascades related pathways (Figure 4B). To further explore the influence of IGF2BP2 expression status on the enrichment of signaling pathway, the AD patients in GSE33000 were divided into IGF2BP2 high and low groups, with the whole transcriptome subjected to GSEA. The results indicated that pathways including complement and coagulation cascades, ECM receptor interaction, focal adhesion, cytokine- cytokine receptor interaction, one carbon pool by folate, TGFbeta signaling pathway were significantly enriched in IGF2BP2_high subgroup (Figure 4C). On the other hand, as for GO biological process enrichment, GSEA results were enriched in collagen fibril organization, extracellular structure organization, regulation of vasculature development, and cellular response to vascular endothelial growth factor stimulus (Figure 4D). The common enrichment pathways in the above results, such as ECM receptor interaction, focal adhesion, cytokine-cytokine receptor interaction, and TGF-beta signaling pathway, may be closely related to the effect of IGF2BP2 on AD, thus providing us some insight into the biological effects associated with IGF2BP2.

\section{Construction and validation of the IGF2BP2-related AD diagnosis model}

We then performed lasso regression on IGF2BP2 and the 65 hub genes in black module to construct a diagnostic model for $\mathrm{AD}$. Based on the $\lambda$ value of LASSO regression, two diagnostic models have been constructed: the first one is the model constructed with 38 genes that maximized the predictive performance regardless of the number of genes, and the second one is the model obtained by including a minimum of 20 of the most critical genes at the appropriate sacrifice of diagnostic efficiency (Figure 5A). In addition, we randomly sample $70 \%$ of the samples in GSE33000 as the train Set, and the remaining 30\% as the test Set to judge the internal diagnostic stability of this model. We found that in the train set the AUC of the first model was 0.972, while the second model was 0.959 , which was still a relative high value (Figure 5B). On the other hand, in the Test set the AUC of the first model was 0.95, and the second model was 0.92 (Figure 5C). Moreover, we used the data in GSE48350 and GSE5281 as the external validation set, with the AUC of the first model 0.80, the second model 0.81 (Figure 5D). In summary, the 20gene-model could be used to construct a suitable $A D$ diagnosis model with the least hub genes while maintaining relatively high diagnostic efficiency. This model included the following genes: TNFRSF11B, GYPC, TP53I11, F10, PKP2, FCGRT, PRRX2, PRELP, BMP6, MRC2, AOX1, PRDM6, STRA6, PTGFR, CFH, SLC22A3, LOC388630, ANXA2P2, COL1A1 and IGF2BP2.

\section{M6A-dependent mechanism between IGF2BP2 and genes in AD diagnostic model}

As a classical RNA binding protein, IGF2BP2 was identified as a m6A reader protein in 2018. The binding between IGF2BP2 and its targets could increase the stability of mRNAs, thereupon promote the expression of the downstream mRNAs and proteins. After WGCNA and LASSO analysis, we got an IGF2BP2-related diagnostic model containing 20 genes. Here we presumed that IGF2BP2 might specifically bind with some of these genes in a m6A-dependent manner. To explore this mechanism, we first searched the possible genes that contained m6A modification sites with high confidence in 20 hub genes using SRAMP. Then, in RMBase, we further predicted the specific binding of IGF2BP2 to m6A sites of target mRNAs. Ultimately, TP53I11, PKP2, BMP6, CFH and COL1A1 were preliminarily confirmed to possess "very high confidence" m6A binding sites with IGF2BP2 (Figure 6A-6E). These binding sites had the value of subsequent experimental verification, and might be able to explain the molecular mechanism of IGF2BP2 promoting the pathogenesis and development of $\mathrm{AD}$.

\section{DISCUSSION}

Accumulation studies have shown that m6A, as a dynamic and reversible regulatory biomarker [24], is related to nervous system development and neurodegenerative diseases [31-33], but its regulatory mechanism is still unclear. Experiments have confirmed 

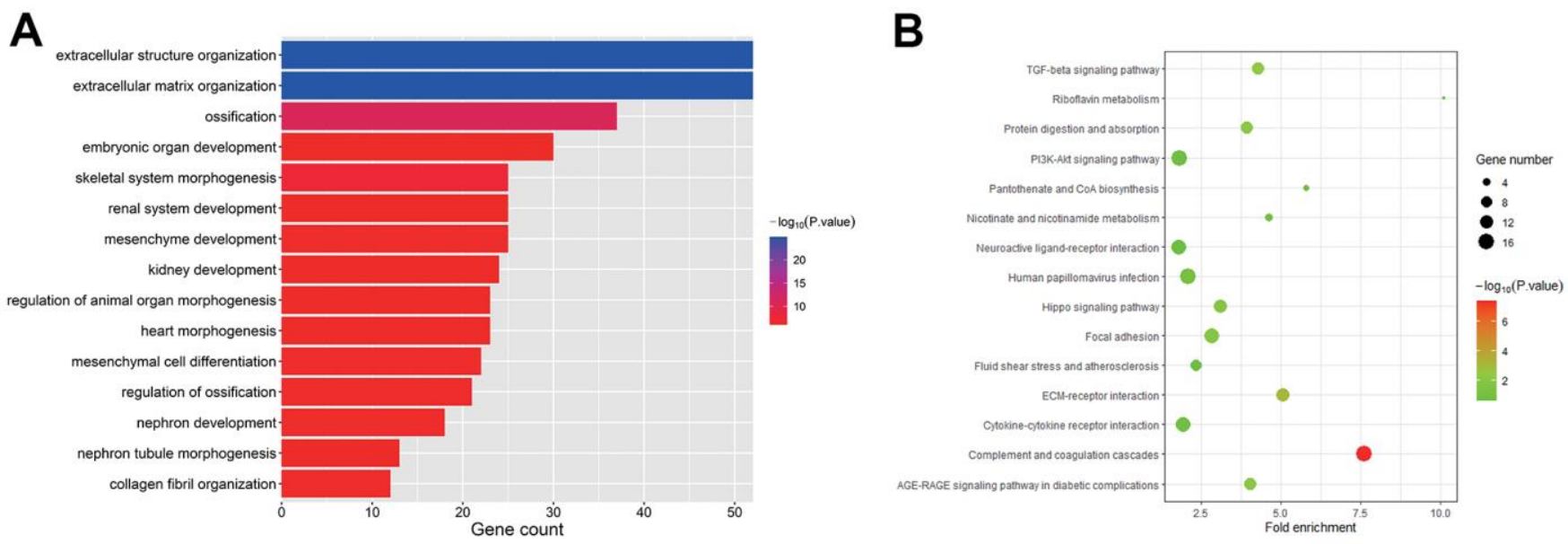

C
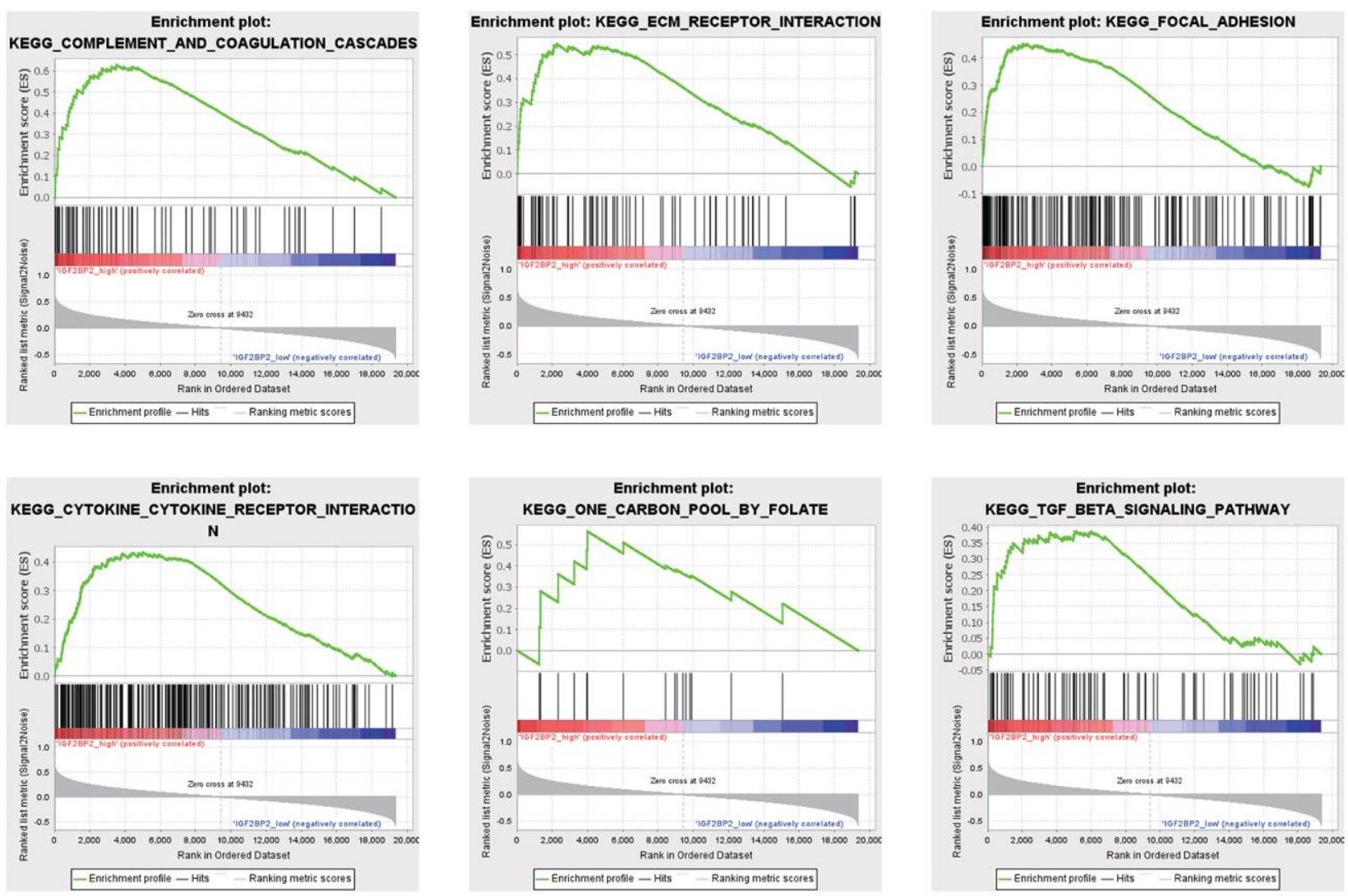

D
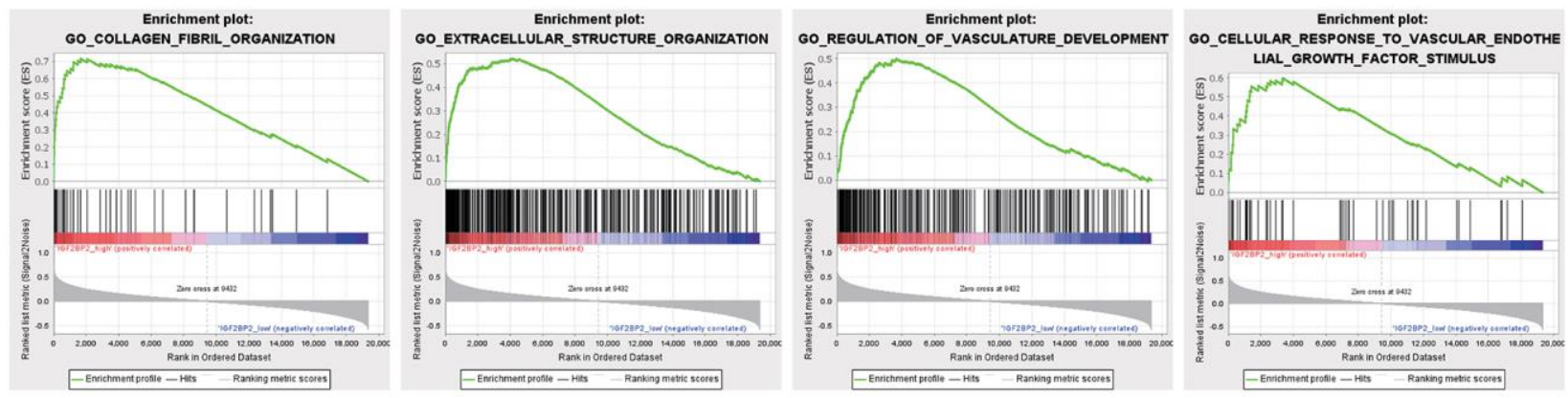

Figure 4. Pathway analysis in DEGS. (A) Biological processes of 440 DEGs in black module. (B) KEGG analysis of 440 DEGs in black module. (C) KEGG pathways enriched in IGF2BP2-high by GSEA. (D) GO biological processes enriched in IGF2BP2-high by GSEA. 
that m6A epitranscriptome plays an important part in synaptic plasticity, neuron development, stress response and cognition [28, 29, 47, 48]. M6A signaling influences learning and memory. Given that learning and memory disorders are clinical features of $\mathrm{AD}$, decrease of $\mathrm{m} 6 \mathrm{~A}$ signaling might be related to the pathophysiology of AD [49]. M6A methylations may be potential biomarkers for cognitive dysfunction such as $\mathrm{AD}$, mild cognitive impairment, and vascular dementia [50]. Mutations in genes which encoding the neuronal glycoprotein m6A have link with psychiatric disorders such as Alzheimer's disease [51]. In previous studies, pathway analyses have predicted the potential effect of m6A methylation RNA
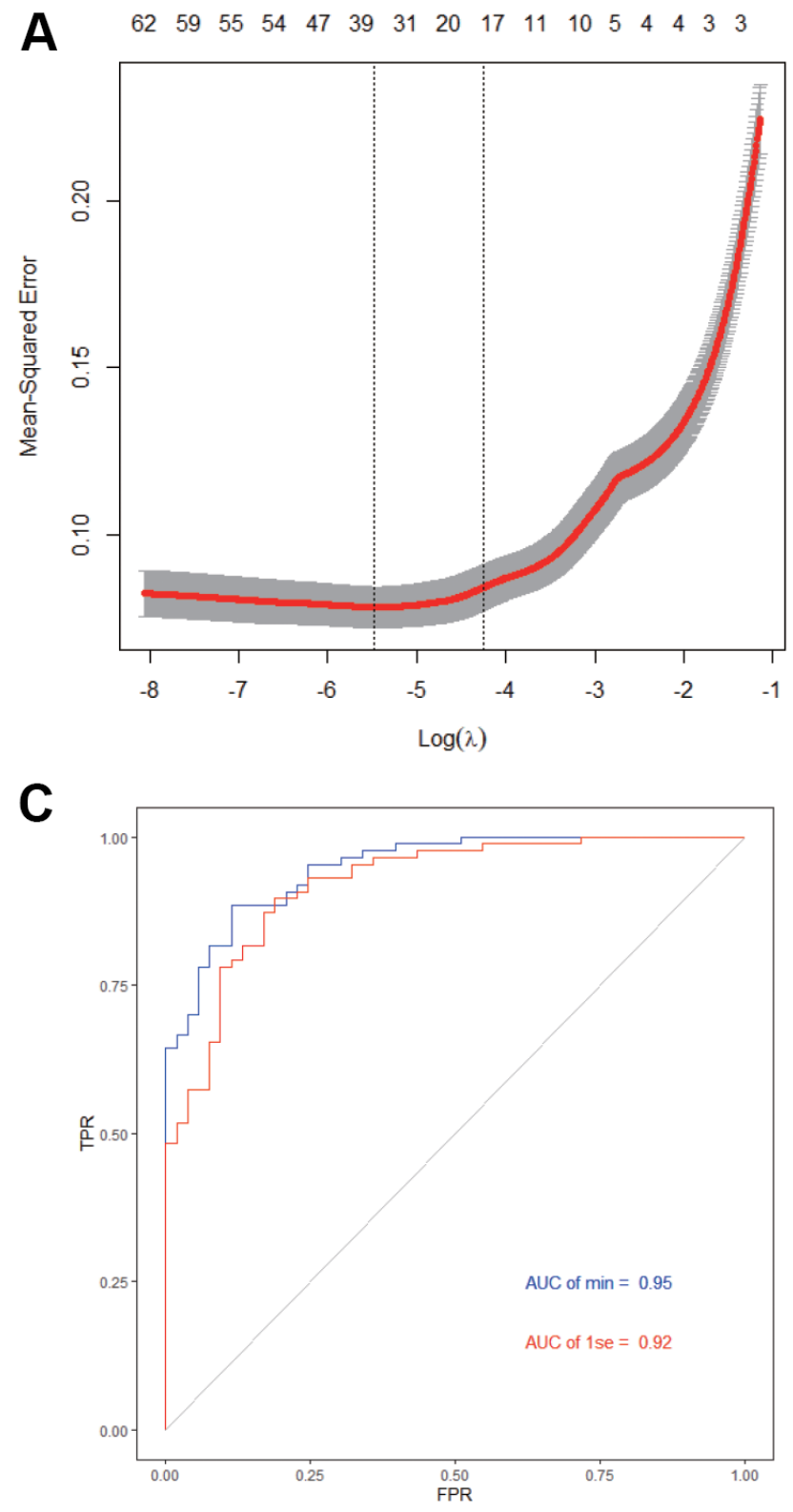

in $\mathrm{AD}$, and the high-throughput sequencing of $\mathrm{m} 6 \mathrm{~A}$ RNA methylation alterations in $\mathrm{AD}$ and $\mathrm{C} 57 \mathrm{BL} / 6$ mice was also verified this association [52, 53]. Besides, m6A controls key gene expression in $\mathrm{AD}$ - related pathways, which indicates that $\mathrm{m} 6 \mathrm{~A}$ renders its essential roles in aging and neurodegenerative diseases [54]. In our study, we found that IGF2BP2, as a m6A reader, increased in $\mathrm{AD}$ patients than in normal people, which might indicate a potential relationship with the occurrence of AD.

As a reader of m6A, IGF2BP2 is associated with carcinogenesis, and has been tested to be associated with the occurrence and prognosis of various cancers

B
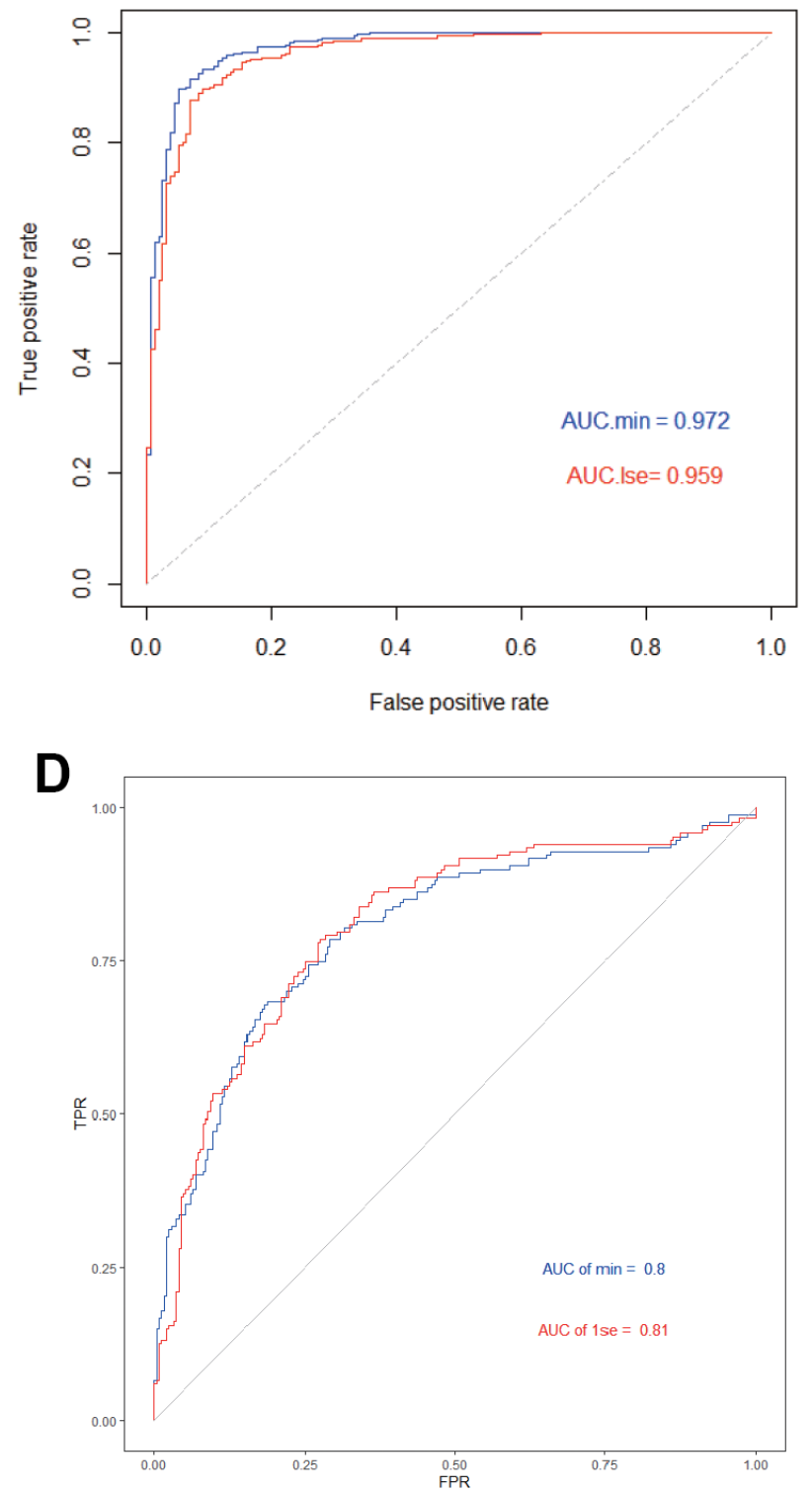

Figure 5. Construction and validation of AD diagnosis model. (A) LASSO model. (B) ROC curves analysis in train set. (C) ROC curves analysis in test set. (D) ROC curves analysis in validation. 
including colorectal cancer [55], gastrointestinal cancer [56], endometrial cancer [57], pancreas cancer [58], breast cancer [59] and Head and Neck Squamous Cell Carcinoma [60]. During the progression of colorectal cancer, LINRIS prevents K139 ubiquitination of IGF2BP2, thereby maintaining its stability. This process prevents IGF2BP2 degradation through the autophagy-lysosomal pathway, which is further related to MYC-mediated glycolysis. Besides, studies confirmed that miR-34a silence resulted in IGF2BP3 activation, which was related with gastric tumorigenesis and differences in prognosis [61]. However, its association with $\mathrm{AD}$ is not clear. We further explored the genes associated with differential expression of

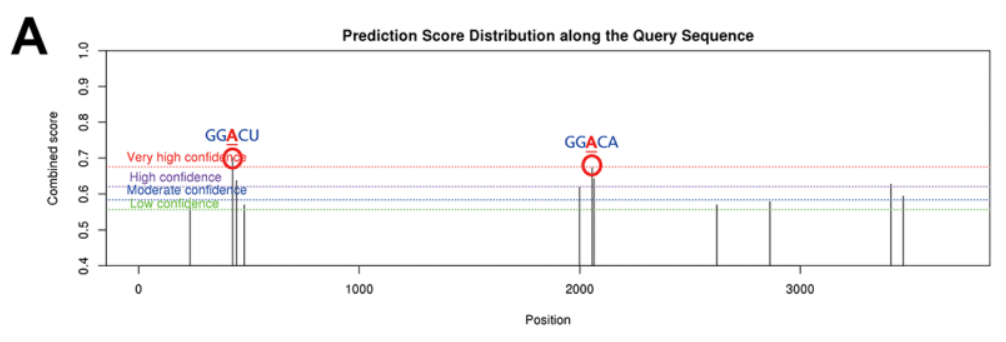

B

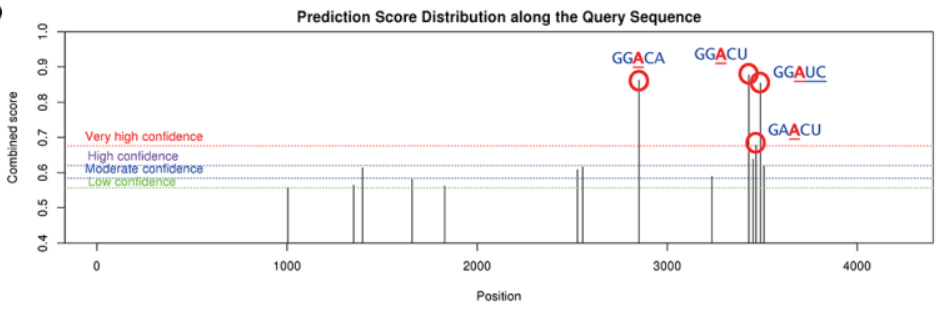

C

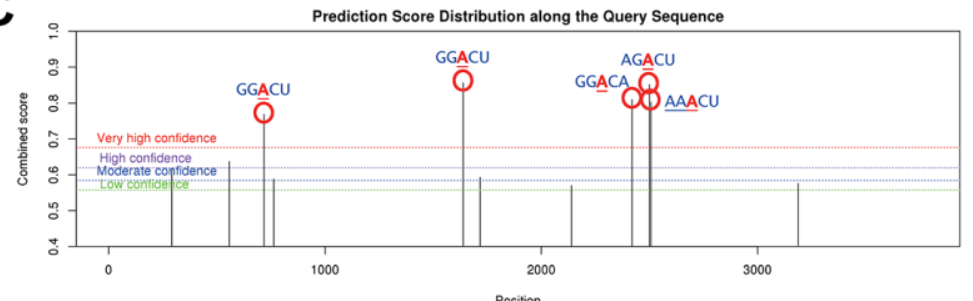

D

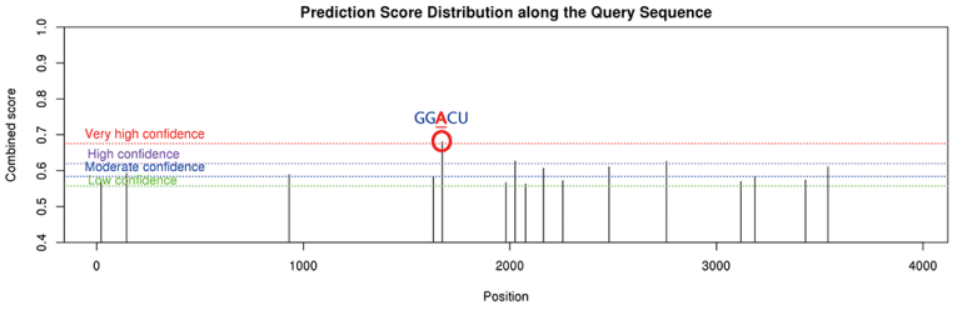

E

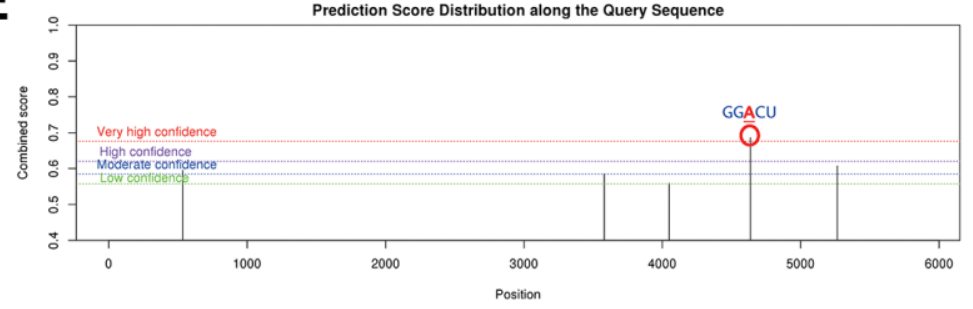

TP53I11 mRNA

IGF2BP2

Chr11:44955979<smiles>C1CCCCCC1</smiles>

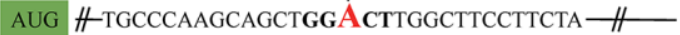

PKP2 mRNA

Chr12: 32945066

IGF2BP2

aug \#- attcatgtggaAggGÁcattaAtccaAtaAa \# \#

PKP2 mRNA

IGF2BP2

Chr12: 32944451

(Me)

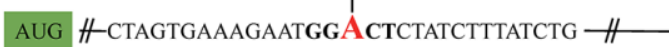

PKP2 mRNA

Chr12: 32944489

IGF2BP2

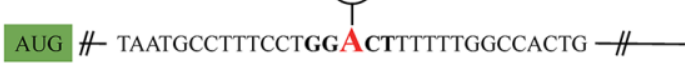

BMP6 mRNA

IGF2BP2

Chr6:7880683

(Me)

aug \#-aCgatgagactTtgGACtatctCatgccagt \#

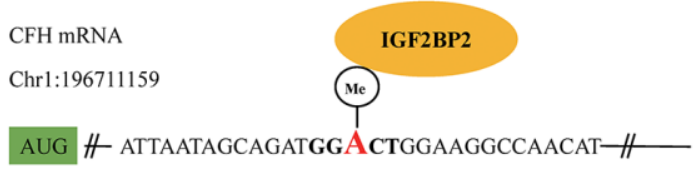

COL1A1 mRNA

IGF2BP2

Chr17:48262802

(Me)

aUg \#-CCCCCCAaccCaAgGACtgacaAgCaAcCCA \#

Figure 6. The m6A mechanism of IGF2PB2 and its downstream mRNA targets. The m6A mechanism of IGF2PB2 and TP53 (A), PKP2 (B), BMP6 (C), CFH (D), COL1A1 (E). 
IGF2BP2, and a total of 17 AD-related modules were identified based on WGCNA data. Furthermore, according to GS $>0.4$ and $M M>0.9$, a total of $65 \mathrm{hub}$ genes were identified eventually.

We further explored the potential pathways related to AD. Pathway enrichment analysis indicated that gene modules related to IGF2BP2 are significantly enriched in ECM receptor interaction, focal adhesion, cytokinecytokine receptor interaction and TGF-beta signaling pathway, which may participate in the occurrence of AD. Many pathways have been confirmed to be related to AD. For example, increasing studies have found that the expression of cytokine-cytokine receptor interaction pathway in $\mathrm{AD}$ is increased [62, 63]. Moreover, TGFbeta signaling pathway may serve as a neurotrophic pathway that satisfies the important protective and survival effects of neurons. It acts as a potential target of neurodegenerative diseases, and is critical in the pathogenesis of $\mathrm{AD}[64,65]$.

In addition, we used IGF2BP2 and 65 hub genes to construct a 20-gene-based diagnostic model. Both training set and test set showed a high AUC value with this lasso model using ROC curve analysis, which is also verified in an independent verification dataset. This meant our diagnostic model might provide a novel idea for the diagnosis of AD.

Finally, we searched for the possible m6A mechanism of IGF2PB2 in 20 hub genes. Further studies have shown that TP53I11, PKP2, BMP6, CFH and COL1A1 had $\mathrm{m} 6 \mathrm{~A}$ and could specifically bind with IGF2PB2. It can be seen that IGF2PB2 probably acts as m6A "reader" that binds to TP53I11, PKP2, BMP6, CFH and COL1A1 m6A, and ultimately leads to AD. Nevertheless, we did not find that the remaining hub genes had m6A or specific binding to IGF2PB2, which might be explained by other function of IGF2PB2 [66, 67].

Our research used bioinformatics methods to reveal the possible molecular mechanisms and built a diagnostic model for AD. However, more key genes and specific signaling pathways underlying $A D$ need to be further verified through cell and animal experiments. On the other hand, to what extent the increase of IGF2BP2 expression in AD patients promotes the occurrence and development of $\mathrm{AD}$ still remains to be tested.

In summary, our study proved that high expression of IGF2BP2 may associate with the increase of the PKP2 through m6A association mechanism, which may further lead to the occurrence of AD. Besides, a diagnostic model was constructed and validated based on that.

\section{MATERIALS AND METHODS}

\section{Datasets acquisition}

Three data sets (GSE33000, GSE5281 and GSE48350) were selected from GEO database (https://www.ncbi.nlm.nih.gov/geo/) for this study. Among them, GSE33000 was based on GPL4372 platform including postmortem prefrontal cortex samples of $310 \mathrm{AD}$ patients and 157 normal people. The "getGEO" function from "GEOquery" package in $\mathrm{R}$ was applied for data downloading of this dataset. Besides, GSE5281 included brain tissue samples of 87 $\mathrm{AD}$ patients and 74 normal people, GSE48350 included $80 \mathrm{AD}$ patients and 173 normal people. Both datasets were based on GPL570 platform. Thus, the "getGEOSuppFiles" function from "GEOquery" package was applied for downloading the raw data of these datasets, and the "justRMA" function from "affy" package was applied for the normalization of them.

\section{Differentially expressed genes (DEGs) identification}

The "limma" package from $\mathrm{R}$ was applied for DEG analysis in this study. For the selected datasets, we select the median expression of IGF2BP2 as the cutoff point to divide AD samples into IGF2BP2_high and IGF2BP2_low subgroups. DEG analysis was then conducted between $\mathrm{AD}$ and normal brain tissues and between IGF2BP2_high and IGF2BP2_low subgroups by $\operatorname{lmFit}$ and eBayes methods. $\mathrm{P}<0.05$ adjusted by the false discovery rate (FDR) was considered as significant. The intersection of the DEGs obtained from the two analyses was defined as IGF2BP2-related AD genes.

\section{Weight gene correlation network analysis (WGCNA) and hub genes identification}

After getting IGF2BP2-related AD genes, WGCNA analysis was performed using "WGCNA" package in $\mathrm{R}$ for GSE33000 dataset. Briefly, "hclust" function was used to hierarchical clustering analysis; then, the soft thresholding power value was calculated by "pickSoftThreshold" function; next, the "blockwiseModules" function was used for constructing co-expression network in IGF2BP2_high and IGF2BP2_low subgroups of AD patients, the module that was mostly correlated with IGF2BP2_high or IGF2BP2_low subgroups was defined as the most valuable module and was selected for further screening. Gene Significance (GS) > 0.4 and Module Membership (MM) > 0.9 was considered as threshold to screen hub genes in the most valuable module. 
Gene Ontology (GO), Kyoto Encyclopedia of Genes and Genomes Pathway (KEGG pathway) and Gene Set Enrichment Analysis (GSEA)

Using enrichGO and enrichKEGG function in "clusterProfiler" package, GO and KEGG pathway analysis were performed based on genes in the most valuable module in WGCNA analysis. Furthermore, Gene Set Enrichment Analysis (GSEA) provided by the JAVA program (Version 4.0.3) with MSigDB v6.1 was applied to explore the downstream biological processes affected by differential expression of IGF2BP2.

\section{Construction and validation of the diagnostic model for AD}

To build a diagnostic model that could maximally distinguish $\mathrm{AD}$ from normal brain samples, least absolute shrinkage and selection operator (LASSO) regression was applied using "glmnet" package to select most representative features in hub genes obtained from the most valuable module in WGCNA analysis. A model index for each sample was created using the regression coefficients from the LASSO analysis to weight the expression value of the selected genes with the following formula:

$$
\text { Diagnostic Index }=\sum_{i=1}^{n} \operatorname{Coef}_{i} * x_{i}
$$

where Coef $_{i}$ means the coefficients for each gene, $x_{i}$ is the expression value of each gene.

Then, samples in GES33000 dataset were randomly assigned to the training set (70\%) and test set (30\%) for internal test. GSE5281 and GSE48350 datasets were applied for external validation of our diagnostic model. The "ROCR" package was used for drawing ROC curves for the training, testing and validation datasets respectively.

\section{The m6A mechanism between IGF2PB2 and hub genes}

To initially explore whether IGF2BP2 and hub genes from WGCNA and LASSO analysis could constitute a m6A-dependent mechanism, SRAMP online database (http://www.cuilab.cn/sramp) and RMBase V2.0 online tools were applied. SRAMP could predict the precise location of m6A modification on mRNAs and provide the confidence of every modification site, while RMBase V2.0 could further inquire whether these modification sites could be specifically recognized and bounded by IGF2BP2.

\section{Abbreviations}

AD: Alzheimer's disease; DEG: differentially expressed gene; WGCNA: weight gene correlation analysis; m6A: N6-methyladenosine; IGF2BP2: Insulin-like growth factor 2 mRNA binding protein 2; GEO: Gene Expression Omnibus; FDR: false discovery rate; GO: Gene Ontology; KEGG: Kyoto Encyclopedia of Genes and Genomes; GSEA: Gene set enrichment analysis; LASSO: least absolute shrinkage and selection operator.

\section{AUTHOR CONTRIBUTIONS}

Conceptualization, Wenzhe Gao and Yalin Lliu; methodology, Yanyao Deng; software, Yanyao Deng; validation, Yanyao Deng; formal analysis, Yanyao Deng; investigation, Wenzhe Gao; data curation, Wenzhe Gao; writing - original draft preparation, Yalin Lliu; writing - review and editing, Hongwei Zhu, Shuhan, Le Xiao and Chao Liu; project administration, Wenzhe Gao; funding acquisition, Hongwei Zhu. All authors have read and agreed to the published version of the manuscript."

\section{ACKNOWLEDGMENTS}

We appreciated GENE EXPRESSION OMNIBUS (GEO) of The National Center for Biotechnology Information (NCBI) which provided all the data included in this study. GSE33000: https://www.ncbi.nlm. nih.gov/geo/query/acc.cgi?acc=GSE33000; GSE5281: https://www.ncbi.nlm.nih.gov/geo/query/acc.cgi?acc=GS E5281; GSE48350: https://www.ncbi.nlm.nih.gov/geo/ query/acc.cgi?acc=GSE48350.

\section{CONFLICTS OF INTEREST}

The authors declare that they have no conflicts of interest.

\section{FUNDING}

This article was supported by the following fundings: (1) Hunan Provincial Science and Technology Plan Project (No. 2019JJ80066); (2) Scientific Research Project of Health and Family Planning Commission of Hunan Province of China (No. B20-17202); (3) National Natural Science Foundation for Young Scholars of China (No. 82000614).

\section{Editorial note}

\&This corresponding author has a verified history of publications using a personal email address for correspondence. 


\section{REFERENCES}

1. Lynch C. World Alzheimer Report 2019: Attitudes to dementia, a global survey. Alzheimers Dement. 2020; 16: e038255.

https://doi.org/10.1002/alz.038255

2. Scheltens $P$, Blennow K, Breteler MM, de Strooper B, Frisoni GB, Salloway S, Van der Flier WM. Alzheimer's disease. Lancet. 2016; 388:505-17. https://doi.org/10.1016/S0140-6736(15)01124-1 PMID:26921134

3. Ballard C, Gauthier S, Corbett A, Brayne C, Aarsland D, Jones E. Alzheimer's disease. Lancet. 2011; 377:1019-31. https://doi.org/10.1016/S0140-6736(10)61349-9 PMID:21371747

4. $\operatorname{Kim} \mathrm{A}$, Kim S, Park KW, Park KH, Youn YC, Lee DW, Lee JY, Lee JH, Jeong JH, Choi SH, Han HJ, Kim S, Na S, et al. A Comparative Evaluation of the KDSQ-C, AD8, and SMCQ as a Cognitive Screening Test to Be Used in National Medical Check-ups in Korea. J Korean Med Sci. 2019; 34:e111.

https://doi.org/10.3346/jkms.2019.34.e111

PMID: $\underline{30977313}$

5. Sperling RA, Aisen PS, Beckett LA, Bennett DA, Craft S, Fagan AM, Iwatsubo T, Jack CR Jr, Kaye J, Montine TJ, Park DC, Reiman EM, Rowe CC, et al. Toward defining the preclinical stages of Alzheimer's disease: recommendations from the National Institute on Aging-Alzheimer's Association workgroups on diagnostic guidelines for Alzheimer's disease. Alzheimers Dement. 2011; 7:280-92.

https://doi.org/10.1016/j.jalz.2011.03.003

PMID:21514248

6. Mielke MM, Vemuri $P$, Rocca WA. Clinical epidemiology of Alzheimer's disease: assessing sex and gender differences. Clin Epidemiol. 2014; 6:37-48.

https://doi.org/10.2147/CLEP.S37929 PMID:24470773

7. Donohue MC, Sperling RA, Petersen R, Sun CK, Weiner $\mathrm{MW}$, Aisen PS, and Alzheimer's Disease Neuroimaging Initiative. Association Between Elevated Brain Amyloid and Subsequent Cognitive Decline Among Cognitively Normal Persons. JAMA. 2017; 317:2305-16.

https://doi.org/10.1001/jama.2017.6669

PMID:28609533

8. Petersen RC, Wiste HJ, Weigand SD, Rocca WA, Roberts RO, Mielke MM, Lowe VJ, Knopman DS, Pankratz VS, Machulda MM, Geda YE, Jack CR Jr. Association of Elevated Amyloid Levels With Cognition and Biomarkers in Cognitively Normal People From the Community. JAMA Neurol. 2016; 73:85-92.

https://doi.org/10.1001/jamaneurol.2015.3098 PMID:26595683
9. Papp KV, Rentz DM, Mormino EC, Schultz AP, Amariglio RE, Quiroz Y, Johnson KA, Sperling RA. Cued memory decline in biomarker-defined preclinical Alzheimer disease. Neurology. 2017; 88:1431-8.

https://doi.org/10.1212/WNL.0000000000003812 PMID:28283594

10. Benzinger TL, Blazey $T$, Jack CR Jr, Koeppe RA, Su Y, Xiong C, Raichle ME, Snyder AZ, Ances BM, Bateman RJ, Cairns NJ, Fagan AM, Goate A, et al. Regional variability of imaging biomarkers in autosomal dominant Alzheimer's disease. Proc Natl Acad Sci USA. 2013; 110:E4502-9.

https://doi.org/10.1073/pnas.1317918110 PMID:24194552

11. Bateman RJ, Xiong $C$, Benzinger $T L$, Fagan $A M$, Goate A, Fox NC, Marcus DS, Cairns NJ, Xie X, Blazey TM, Holtzman DM, Santacruz A, Buckles V, et al, and Dominantly Inherited Alzheimer Network. Clinical and biomarker changes in dominantly inherited Alzheimer's disease. N Engl J Med. 2012; 367:795-804.

https://doi.org/10.1056/NEJMoa1202753 PMID:22784036

12. Fleisher AS, Chen K, Quiroz YT, Jakimovich L, Gutierrez Gomez M, Langois CM, Langbaum JB, Roontiva A, Thiyyagura P, Lee W, Ayutyanont N, Lopez L, Moreno S, et al. Associations between biomarkers and age in the presenilin 1 E280A autosomal dominant Alzheimer disease kindred: a cross-sectional study. JAMA Neurol. 2015; 72:316-24.

https://doi.org/10.1001/jamaneurol.2014.3314 PMID:25580592

13. Fagan AM, Xiong $C$, Jasielec MS, Bateman RJ, Goate $A M$, Benzinger $T L$, Ghetti $B$, Martins RN, Masters $C L$, Mayeux R, Ringman JM, Rossor MN, Salloway S, et al, and Dominantly Inherited Alzheimer Network. Longitudinal change in CSF biomarkers in autosomaldominant Alzheimer's disease. Sci Transl Med. 2014; 6:226ra30.

https://doi.org/10.1126/scitranslmed.3007901 PMID:24598588

14. Montine TJ, Phelps CH, Beach TG, Bigio EH, Cairns NJ, Dickson DW, Duyckaerts C, Frosch MP, Masliah E, Mirra SS, Nelson PT, Schneider JA, Thal DR, et al, and National Institute on Aging, and Alzheimer's Association. National Institute on Aging-Alzheimer's Association guidelines for the neuropathologic assessment of Alzheimer's disease: a practical approach. Acta Neuropathol. 2012; 123:1-11. https://doi.org/10.1007/s00401-011-0910-3 PMID:22101365

15. Hyman BT, Phelps CH, Beach TG, Bigio EH, Cairns NJ, Carrillo MC, Dickson DW, Duyckaerts C, Frosch MP, 
Masliah E, Mirra SS, Nelson PT, Schneider JA, et al. National Institute on Aging-Alzheimer's Association guidelines for the neuropathologic assessment of Alzheimer's disease. Alzheimers Dement. 2012; 8:1-13.

https://doi.org/10.1016/j.jalz.2011.10.007 PMID:22265587

16. Neueder A. RNA-Mediated Disease Mechanisms in Neurodegenerative Disorders. J Mol Biol. 2019; 431:1780-91.

https://doi.org/10.1016/i.jmb.2018.12.012

PMID:30597161

17. Sanchez-Mut JV, Gräff J. Epigenetic Alterations in Alzheimer's Disease. Front Behav Neurosci. 2015; 9:347.

https://doi.org/10.3389/fnbeh.2015.00347 PMID:26734709

18. De Jager PL, Srivastava G, Lunnon K, Burgess J, Schalkwyk LC, Yu L, Eaton ML, Keenan BT, Ernst J, McCabe C, Tang A, Raj T, Replogle J, et al. Alzheimer's disease: early alterations in brain DNA methylation at ANK1, BIN1, RHBDF2 and other loci. Nat Neurosci. 2014; 17:1156-63.

https://doi.org/10.1038/nn.3786 PMID:25129075

19. Lunnon K, Smith R, Hannon E, De Jager PL, Srivastava G, Volta M, Troakes C, Al-Sarraj S, Burrage J, Macdonald R, Condliffe D, Harries LW, Katsel P, et al. Methylomic profiling implicates cortical deregulation of ANK1 in Alzheimer's disease. Nat Neurosci. 2014; 17:1164-70.

https://doi.org/10.1038/nn.3782

PMID:25129077

20. Marzi SJ, Leung SK, Ribarska T, Hannon E, Smith AR, Pishva E, Poschmann J, Moore K, Troakes C, Al-Sarraj S, Beck S, Newman S, Lunnon K, et al. A histone acetylome-wide association study of Alzheimer's disease identifies disease-associated H3K27ac differences in the entorhinal cortex. Nat Neurosci. 2018; 21:1618-27.

https://doi.org/10.1038/s41593-018-0253-7 PMID:30349106

21. Nativio R, Donahue G, Berson A, Lan Y, Amlie-Wolf A, Tuzer F, Toledo JB, Gosai SJ, Gregory BD, Torres C, Trojanowski JQ, Wang LS, Johnson FB, et al. Dysregulation of the epigenetic landscape of normal aging in Alzheimer's disease. Nat Neurosci. 2018; 21:497-505.

https://doi.org/10.1038/s41593-018-0101-9

PMID:29507413

22. Klein HU, McCabe C, Gjoneska E, Sullivan SE, Kaskow BJ, Tang A, Smith RV, Xu J, Pfenning AR, Bernstein BE, Meissner A, Schneider JA, Mostafavi S, et al. Epigenome-wide study uncovers large-scale changes in histone acetylation driven by tau pathology in aging and Alzheimer's human brains. Nat Neurosci. 2019; 22:37-46.

https://doi.org/10.1038/s41593-018-0291-1 PMID:

23. Saletore Y, Meyer K, Korlach J, Vilfan ID, Jaffrey S, Mason CE. The birth of the Epitranscriptome: deciphering the function of RNA modifications. Genome Biol. 2012; 13:175.

https://doi.org/10.1186/gb-2012-13-10-175 PMID:23113984

24. Niu Y, Zhao X, Wu YS, Li MM, Wang XJ, Yang YG. N6methyl-adenosine (m6A) in RNA: an old modification with a novel epigenetic function. Genomics Proteomics Bioinformatics. 2013; 11:8-17.

https://doi.org/10.1016/j.gpb.2012.12.002 PMID:23453015

25. Zhao BS, Roundtree IA, He C. Publisher Correction: Post-transcriptional gene regulation by mRNA modifications. Nat Rev Mol Cell Biol. 2018; 19:808. https://doi.org/10.1038/s41580-018-0075-1 PMID:30341428

26. Schwartz S. Cracking the epitranscriptome. RNA. 2016; 22:169-74.

https://doi.org/10.1261/rna.054502.115 PMID:26787305

27. Luo J, Liu H, Luan S, He C, Li Z. Aberrant Regulation of mRNA $\mathrm{m}^{6} \mathrm{~A}$ Modification in Cancer Development. Int J Mol Sci. 2018; 19:2515. https://doi.org/10.3390/ijms19092515 PMID:30149601

28. Widagdo J, Anggono V. The m6A-epitranscriptomic signature in neurobiology: from neurodevelopment to brain plasticity. J Neurochem. 2018; 147:137-52.

https://doi.org/10.1111/inc.14481 PMID:29873074

29. Flamand MN, Meyer KD. The epitranscriptome and synaptic plasticity. Curr Opin Neurobiol. 2019; 59:41-8.

https://doi.org/10.1016/i.conb.2019.04.007 PMID:31108373

30. Livneh I, Moshitch-Moshkovitz S, Amariglio N, Rechavi G, Dominissini D. The $\mathrm{m}^{6} \mathrm{~A}$ epitranscriptome: transcriptome plasticity in brain development and function. Nat Rev Neurosci. 2020; 21:36-51. https://doi.org/10.1038/s41583-019-0244-z PMID:31804615

31. Meyer KD, Saletore Y, Zumbo P, Elemento O, Mason $\mathrm{CE}$, Jaffrey SR. Comprehensive analysis of mRNA methylation reveals enrichment in 3' UTRs and near stop codons. Cell. 2012; 149:1635-46.

https://doi.org/10.1016/i.cell.2012.05.003 PMID:22608085 
32. Widagdo J, Zhao QY, Kempen MJ, Tan MC, Ratnu VS, Wei W, Leighton L, Spadaro PA, Edson J, Anggono V, Bredy TW. Experience-Dependent Accumulation of N6Methyladenosine in the Prefrontal Cortex Is Associated with Memory Processes in Mice. J Neurosci. 2016; 36:6771-7.

https://doi.org/10.1523/JNEUROSCI.4053-15.2016 PMID:27335407

33. Li H, Ren Y, Mao K, Hua F, Yang Y, Wei N, Yue C, Li D, Zhang $\mathrm{H}$. FTO is involved in Alzheimer's disease by targeting TSC1-mTOR-Tau signaling. Biochem Biophys Res Commun. 2018; 498:234-9.

https://doi.org/10.1016/j.bbrc.2018.02.201 PMID:29501742

34. Li L, Zang L, Zhang F, Chen J, Shen H, Shu L, Liang F, Feng C, Chen D, Tao H, Xu T, Li Z, Kang Y, et al. Fat mass and obesity-associated (FTO) protein regulates adult neurogenesis. Hum Mol Genet. 2017; 26:2398-411.

https://doi.org/10.1093/hmg/ddx128

PMID:28398475

35. Walters BJ, Mercaldo V, Gillon CJ, Yip M, Neve RL, Boyce FM, Frankland PW, Josselyn SA. The Role of The RNA Demethylase FTO (Fat Mass and ObesityAssociated) and mRNA Methylation in Hippocampal Memory Formation. Neuropsychopharmacology. 2017; 42:1502-10.

https://doi.org/10.1038/npp.2017.31

PMID:28205605

36. Koranda JL, Dore L, Shi H, Patel MJ, Vaasjo LO, Rao MN, Chen K, Lu Z, Yi Y, Chi W, He C, Zhuang X. Mettl14 Is Essential for Epitranscriptomic Regulation of Striatal Function and Learning. Neuron. 2018; 99:283-92.e5.

https://doi.org/10.1016/i.neuron.2018.06.007 PMID:30056831

37. Shi $H$, Zhang $X$, Weng $Y L$, Lu Z, Liu $Y$, Lu Z, Li J, Hao $P$, Zhang $Y$, Zhang $F, W u ~ Y$, Delgado JY, Su Y, et al. $m^{6} A$ facilitates hippocampus-dependent learning and memory through YTHDF1. Nature. 2018; 563:249-53. https://doi.org/10.1038/s41586-018-0666-1 PMID:30401835

38. Zhang Z, Wang $M$, Xie D, Huang Z, Zhang L, Yang Y, Ma D, Li W, Zhou Q, Yang YG, Wang XJ. METTL3-mediated $\mathrm{N}^{6}$-methyladenosine mRNA modification enhances long-term memory consolidation. Cell Res. 2018; 28:1050-61.

https://doi.org/10.1038/s41422-018-0092-9

PMID: $\underline{30297870}$

39. Formoso K, Billi SC, Frasch AC, Scorticati C. Tyrosine 251 at the C-terminus of neuronal glycoprotein M6a is critical for neurite outgrowth. J Neurosci Res. 2015; 93:215-29.

https://doi.org/10.1002/jnr.23482

PMID:25242528
40. Formoso K, Garcia MD, Frasch AC, Scorticati C. Evidence for a role of glycoprotein $\mathrm{M} 6 \mathrm{a}$ in dendritic spine formation and synaptogenesis. Mol Cell Neurosci. 2016; 77:95-104.

https://doi.org/10.1016/j.mcn.2016.10.005 PMID:27793698

41. Sato $Y$, Mita S, Fukushima N, Fujisawa H, Saga $Y$, Hirata $\mathrm{T}$. Induction of axon growth arrest without growth cone collapse through the $\mathrm{N}$-terminal region of fourtransmembrane glycoprotein M6a. Dev Neurobiol. 2011; 71:733-46. https://doi.org/10.1002/dneu.20941 PMID:21714103

42. Hu $X$, Peng $W X$, Zhou $H$, Jiang J, Zhou $X$, Huang D, Mo YY, Yang L. IGF2BP2 regulates DANCR by serving as an N6-methyladenosine reader. Cell Death Differ. 2020; 27:1782-94.

https://doi.org/10.1038/s41418-019-0461-z PMID:31804607

43. Wang T, Kong S, Tao M, Ju S. The potential role of RNA N6-methyladenosine in Cancer progression. Mol Cancer. 2020; 19:88. https://doi.org/10.1186/s12943-020-01204-7 PMID:32398132

44. Zheng HX, Zhang XS, Sui N. Advances in the profiling of $\mathrm{N}^{6}$-methyladenosine $\left(\mathrm{m}^{6} \mathrm{~A}\right)$ modifications. Biotechnol Adv. 2020; 45:107656.

https://doi.org/10.1016/j.biotechadv.2020.107656 PMID:33181242

45. Fischer B, Schmoll H, Riederer P, Bauer J, Platt D, PopaWagner A. Complement C1q and C3 mRNA expression in the frontal cortex of Alzheimer's patients. J Mol Med (Berl). 1995; 73:465-71. https://doi.org/10.1007/BF00202265 PMID: 8528750

46. Slevin $\mathrm{M}$, Matou $\mathrm{S}$, Zeinolabediny $\mathrm{Y}$, Corpas $\mathrm{R}$, Weston R, Liu D, Boras E, Di Napoli M, Petcu E, Sarroca S, PopaWagner A, Love S, Font MA, et al. Monomeric Creactive protein--a key molecule driving development of Alzheimer's disease associated with brain ischaemia? Sci Rep. 2015; 5:13281. https://doi.org/10.1038/srep13281 PMID:26335098

47. Engel $M$, Chen $A$. The emerging role of mRNA methylation in normal and pathological behavior. Genes Brain Behav. 2018; 17:e12428.

https://doi.org/10.1111/gbb.12428 PMID:29027751

48. Huang YS, Lu WH. Decoding hidden messages in neurons: insights from epitranscriptome-controlled and specialized ribosome-controlled translation. Curr Opin Neurobiol. 2018; 48:64-70.

https://doi.org/10.1016/i.conb.2017.10.018 PMID:29125978

49. Huang $\mathrm{H}$, Camats-Perna J, Medeiros R, Anggono V, Widagdo J. Altered Expression of the m6A 
Methyltransferase METTL3 in Alzheimer's Disease. eNeuro. 2020; 7:ENEURO.0125-20.2020.

https://doi.org/10.1523/ENEURO.0125-20.2020

PMID:32847866

50. Du B, Zhang Y, Liang M, Du Z, Li H, Fan C, Zhang H, Jiang $\mathrm{Y}, \mathrm{Bi}$ X. N6-methyladenosine (m6A) modification and its clinical relevance in cognitive dysfunctions. Aging (Albany NY). 2021; 13:20716-37.

https://doi.org/10.18632/aging.203457

PMID:34461609

51. Garcia MD, Formoso K, Aparicio GI, Frasch AC, Scorticati C. The Membrane Glycoprotein M6a Endocytic/Recycling Pathway Involves ClathrinMediated Endocytosis and Affects Neuronal Synapses. Front Mol Neurosci. 2017; 10:296.

https://doi.org/10.3389/fnmol.2017.00296

PMID:28979185

52. Han $M$, Liu Z, Xu Y, Liu X, Wang D, Li F, Wang Y, Bi J. Abnormality of m6A mRNA Methylation Is Involved in Alzheimer's Disease. Front Neurosci. 2020; 14:98. https://doi.org/10.3389/fnins.2020.00098 PMID: $\underline{32184705}$

53. Shafik AM, Zhang F, Guo Z, Dai Q, Pajdzik K, Li Y, Kang Y, Yao B, Wu H, He C, Allen EG, Duan R, Jin P. N6methyladenosine dynamics in neurodevelopment and aging, and its potential role in Alzheimer's disease. Genome Biol. 2021; 22:17.

https://doi.org/10.1186/s13059-020-02249-z PMID:33402207

54. Loh D, Reiter RJ. Melatonin: Regulation of Biomolecular Condensates in Neurodegenerative Disorders. Antioxidants (Basel). 2021; 10:1483.

https://doi.org/10.3390/antiox10091483

PMID:34573116

55. Wang Y, Lu JH, Wu QN, Jin Y, Wang DS, Chen YX, Liu J, Luo XJ, Meng Q, Pu HY, Wang YN, Hu PS, Liu ZX, et al. LncRNA LINRIS stabilizes IGF2BP2 and promotes the aerobic glycolysis in colorectal cancer. Mol Cancer. 2019; 18:174.

https://doi.org/10.1186/s12943-019-1105-0

PMID:31791342

56. Wang X, Guan D, Wang D, Liu H, Wu Y, Gong W, Du M, Chu H, Qian J, Zhang Z. Genetic variants in m6A regulators are associated with gastric cancer risk. Arch Toxicol. 2021; 95:1081-8.

https://doi.org/10.1007/s00204-020-02958-1

PMID:33398416

57. Hiramatsu K, Yoshino K, Serada S, Yoshihara K, Hori Y, Fujimoto M, Matsuzaki S, Egawa-Takata T, Kobayashi E, Ueda Y, Morii E, Enomoto T, Naka T, Kimura T. Similar protein expression profiles of ovarian and endometrial high-grade serous carcinomas. Br J Cancer. 2016;
114:554-61.

https://doi.org/10.1038/bjc.2016.27 PMID:26889980

58. Xu X, Yu Y, Zong K, Lv P, Gu Y. Up-regulation of IGF2BP2 by multiple mechanisms in pancreatic cancer promotes cancer proliferation by activating the PI3K/Akt signaling pathway. J Exp Clin Cancer Res. 2019; 38:497. https://doi.org/10.1186/s13046-019-1470-y PMID:31852504

59. McMullen ER, Gonzalez ME, Skala SL, Tran M, Thomas D, Djomehri SI, Burman B, Kidwell KM, Kleer CG. CCN6 regulates IGF2BP2 and HMGA2 signaling in metaplastic carcinomas of the breast. Breast Cancer Res Treat. 2018; 172:577-86.

https://doi.org/10.1007/s10549-018-4960-2 PMID: $\underline{30220054}$

60. Deng X, Jiang Q, Liu Z, Chen W. Clinical Significance of an m6A Reader Gene, IGF2BP2, in Head and Neck Squamous Cell Carcinoma. Front Mol Biosci. 2020; 7:68.

https://doi.org/10.3389/fmolb.2020.00068 PMID:32391379

61. Zhou $Y$, Huang $T$, Siu $H L$, Wong $C C$, Dong $Y$, Wu $F$, Zhang B, Wu WK, Cheng AS, Yu J, To KF, Kang W. IGF2BP3 functions as a potential oncogene and is a crucial target of miR-34a in gastric carcinogenesis. Mol Cancer. 2017; 16:77.

https://doi.org/10.1186/s12943-017-0647-2 PMID:28399871

62. Grigg I, Ivashko-Pachima Y, Hait TA, Korenková V, Touloumi O, Lagoudaki R, Van Dijck A, Marusic Z, Anicic M, Vukovic J, Kooy RF, Grigoriadis N, Gozes I. Tauopathy in the young autistic brain: novel biomarker and therapeutic target. Transl Psychiatry. 2020; 10:228.

https://doi.org/10.1038/s41398-020-00904-4

PMID:32661233

63. Wang $H$, Li Y, Ryder JW, Hole JT, Ebert PJ, Airey DC, Qian HR, Logsdon B, Fisher A, Ahmed Z, Murray TK, Cavallini A, Bose $S$, et al. Genome-wide RNAseq study of the molecular mechanisms underlying microglia activation in response to pathological tau perturbation in the $\mathrm{rTg} 4510$ tau transgenic animal model. Mol Neurodegener. 2018; 13:65.

https://doi.org/10.1186/s13024-018-0296-y

PMID:30558641

64. Wang H, Liu J, Zong Y, Xu Y, Deng W, Zhu H, Liu Y, Ma C, Huang L, Zhang L, Qin C. miR-106b aberrantly expressed in a double transgenic mouse model for Alzheimer's disease targets TGF- $\beta$ type II receptor. Brain Res. 2010; 1357:166-74.

https://doi.org/10.1016/i.brainres.2010.08.023 PMID:20709030 
65. Wyss-Coray T. Tgf-Beta pathway as a potential target in neurodegeneration and Alzheimer's. Curr Alzheimer Res. 2006; 3:191-5.

https://doi.org/10.2174/156720506777632916

PMID:16842094

66. Zhang X, Xue C, Lin J, Ferguson JF, Weiner A, Liu W, Han $Y$, Hinkle $C$, Li $W$, Jiang $H$, Gosai $S$, Hachet $M$, Garcia BA, et al. Interrogation of nonconserved human adipose lincRNAs identifies a regulatory role of lincADAL in adipocyte metabolism. Sci Transl Med. 2018; 10:eaar5987.

https://doi.org/10.1126/scitranslmed.aar5987 PMID:29925637
67. Liu HB, Muhammad T, Guo Y, Li MJ, Sha QQ, Zhang CX, Liu H, Zhao SG, Zhao H, Zhang H, Du YZ, Sun K, Liu K, et al. RNA-Binding Protein IGF2BP2/IMP2 is a Critical Maternal Activator in Early Zygotic Genome Activation. Adv Sci (Weinh). 2019; 6:1900295.

https://doi.org/10.1002/advs.201900295

PMID: $\underline{1406667}$ 